\title{
Spinal Cord Injury - Important Terminologies and Basic Care
}

\author{
${ }^{1}$ Department of Orthopaedics, Jawaharlal Nehru Medical College, India \\ ${ }^{2}$ Department of Orthopaedics, Jawaharlal Nehru Medical College, India \\ ${ }^{3}$ Department of Orthopaedics, Jawaharlal Nehru Medical College, India \\ ${ }^{4}$ Senior Resident, KEM Hospital, India \\ ${ }^{5}$ Department of Orthopaedics, Jawaharlal Nehru Medical College, India \\ ${ }^{6}$ Department of Spine Surgery, Dr H L Hiranandani Hospital, India
}

Sanjay Deshpande ${ }^{1}$, Nitin Samal ${ }^{2}$, Sandeep Wagh ${ }^{3}$, Tanmay Dua ${ }^{4}$, Sohael Khan ${ }^{5 *}$ and Pradeep K Sing

Submission: July 20, 2017; Published: July 24, 2017

*Corresponding author: Sohael Khan, Assistant Professor \& Consultant Spine Division, Department of Orthopedics, Jawaharlal Nehru Medical College, Wardha, Maharashtra, India, Email: drsohaelkhan@hotmail.com

\section{Commentary}

A spinal cord injury is most traumatic event in life of any individual. It may happen to anyone, anywhere, and at any time. Baseline nursing care knowledge must be taught and should be included in curricula of all health care professionals. Nursing care in patients with spinal cord injury (SCI) is mainly intended towards prevention of further injury to spinal cord and complications related to $\mathrm{SCI}$ and reducing morbidity. Spinal cord injury (SCI) is an insult to the spinal cord resulting in a change, either temporary or permanent, in the cord's normal motor, sensory, or autonomic function. Majority of the times spinal cord injury is result of vehicular accidents, fall from height, sports injury and assault. A notable pattern of cervical spine injury is noted where there is practice of carrying load overhead with typical history of acute loss of power when person is deloading the load down.

\section{To clear the terminologies -}

Paraplegia means complete loss of power in lower half of the body inclusive of lower limbs, bladder and bowel while paraparesis is incomplete loss of power in lower half of the body inclusive of lower limbs, bladder and bowel. Quadriplegia is term used to describe paralysis of upper and lower limbs with involvement of bladder and bowel, while quadriparesis means there is partial loss of power in all four limbs especially some segments in upper limbs are spared. Spinal shock is a temporary are flexic stage with loss of autonomic control and muscle tone below the level of injury, which may last for six weeks. First sign of recovery from spinal shock is bulbospongiosus reflex (BSR). It's a polysynaptic reflex. Here glans penis or clitoris is squeezed and anal sphincter contraction is noted clinically and if facilities available may be tested electro physiologically.
Injury may occur due to primary insult or secondary insult. Primary insult is at time of initial injury there may be partial or complete transaction of cord, compression, haemorrhage, or distraction leading to loss of blood supply, while in secondary insult (which may occur over hours to days) as a result of inflammatory process leading to cord and soft tissue oedema leading to ischemia of nerve cells, which may result in irreversible damage of nerve cells and finally lead to permanent disability. The management starts from the site of injury. Immobilization of the injured part of vertebral column is very important and vital to prevent further damage of spinal cord injury. For e.g. if its cervical spine injury immobilize neck with hard cervical collar before shifting patient from site.

Initial management consists of primary BLS \& first aid. Once patient is stable then do thorough clinical examination followed by neurosurgical, orthopedic, and if needed other referrals as per need. Considering patients condition, locate where to admit the case. It may be ICU, neurosurgery ward, if with abdominal injuries then general surgery ward etc. While shifting immobilize entire spine of patient with SCI. Log rolling of patient is of vital importance and it needs enough personals. In cervical spine injury to avoid complications like venous obstruction, airway pressure, aspiration and to give comfort to patient, maintain neck in neutral position with hard cervical collar and as soon as possible change hard cervical collar to two piece collar. A nurse must be well versed with halo and orthotic devices, if needed nurse must be able to release or fasten or reposition the external devices. Always aim towards normal alignment of vertebral column and normal perfusion pressure and oxygenation of spinal cord. 
A thorough clinical examination and neurological assessment is necessary, once examination and assessment is over document it and shift patient to radiological investigations. $\mathrm{X}$ ray picture would give a reasonable level of injury while CT scan will give extent of bony injury. MRI is of gold standard to detect soft tissue injury like transaction of cord, compression of the cord etc. As vital signs can be quite abnormal it's important to regularly check vitals like heart rate, respiration, blood pressure etc. Bradycardia (reduced heart rate) may occur due to unopposed vagal action, during tracheal intubation or endotracheal suction, action required here is continuous monitoring of heart rate and if needed anticholinergic drug medication.

Autonomic controls maintain vasomotor tone thus controlling blood pressure. If there is loss of this autonomic control we may observe vasodilatation leading to hypotension leading to poor perfusion of spinal cord. Action required here is continuous monitoring of blood pressure and adequate hydration of patient (no overloading of fluids which may lead to pulmonary oedema). If needed vasopressor drugs like noradrenalin through intravenous route with continuous monitoring. As there is loss of temperature control, patient usually adapts environmental temperature. Action required here is if environment is cool maintain adequate clothing and room temperature by heating modalities and if it's hot then ensure room cooling.

Respiration is difficult in initial stage as there is spinal cord oedema. Later on depending on injury level, further things are needed in anticipation. If injury is above C4 level as there is paralysis of diaphragm and intercostals muscles, mechanical ventilation is needed. If site is below $\mathrm{C} 4$, diaphragm is spared but still intercostals and other muscles of respiration are paralyzed. In this situation patient may need some times respiratory support. If level is below T6 then there is paralysis of abdominal muscles. Action required for respiratory problems is, monitor type of breathing, pattern, auscultate chest, and monitor SPO2, ETCO2, and ABG. As per need give respiratory support like Oxygen inhalation, nurse head up (Here entire bed is tilted to keep spine aligned), endotracheal intubation, tracheostomy and mechanical ventilation. Always follow strict ventilator associated pneumonia prevention strategies. Maintain well of chest physiotherapy, assisted coughing and BiPAP.

Skin care is needed to prevent pressure sores as skin lacks sensations, Action required here is: Initial baseline skin assessment at time of admission, two hourly change in posture, air mattress, prevent pressure on those areas which are showing early signs of pressure sore. While sponging always check temperature of water, it should not be too hot or cold. Good skin hygiene is to be maintained. Skin should not be kept moist, it must be maintained dry.

For bladder dysfunction indwelling urinary catheterization is done with all aseptic precautions. To prevent complications like UTI, renal \& bladder stones, maintain good catheter care, maintain good hydration. Teach patient or his relatives/care takers, how to take catheter care and frequent clean change of urinary catheter. As far as possible use latex free catheters to prevent latex allergy. Bowel functions are definitely disturbed and may lead to constipation, diarrhea or impaction. To prevent this patient must evacuate his bowel regularly. In case of constipation enough intake of fluids \& fiber intake, use of laxatives, per rectal enemas is needed. For diarrhea change in diet, change in antibiotics, send stool for bacteriological examination. Use of probiotics.

For thromboprophylaxis get regular ankle, knee mobilization by physiotherapy, use sequential calf compression devices. Consult clinical hematologist for developing thromboprophylaxis plan. Maintain good nutrition status. Nasogastric intubation is needed initially to prevent aspirations. Nasogastric intubation has an advantage over orogastric intubation. It allows oral intake as soon as patient is able to protect his airway, as risk of aspiration is reduced. Enough amounts of calories, fluids, fiber and vitamins are needed. Here risk of gastric ulcerations is to be considered and accordingly preventive care is to be introduced.

\section{Prevention of Soft Tissue Contractures}

As there is loss of voluntary control over skeletal muscles, few muscles may be hypertonic, atonic or hypotonic leading to abnormal balance of agonist and antagonist muscles, leading to deformed postures of joints. If joints remain in abnormal position for long time there are all chances of soft tissue, undergoing contractures. To prevent contractures, physiotherapy must be started for range of movements exercises and maintain position of patient in good alignment. At rest foot drop splints, splints for hand etc must be used.

\section{Postural Hypotension}

Because of prolong lying down position in bed and due to loss of sympathetic autonomic nervous system innervations and inability to regulate BP normally with vasoconstriction, while moving from lying down position to sitting and sitting to standing, patient undergoes postural hypotension. Action needed here is before doing attempt upright position take medical approval. Wear an abdominal binder and antiembolic stockings. Maintain good salt and water intake. Elevate head end of the bed by about four to six inches. Gradual elevation of head end, till patients body adjusts to sitting posture. Educate patient and his caretakers.

\section{Autonomic Hyper Reflexia (Dysreflexia)}

Early recognition of Dysreflexia is important. After injury at level of T6 or below patient may face autonomic hyper reflexia. It is characterized by hypertension, bradycardia, severe headache, sweating and blurred vision. Patient is anxious and may have nausea \& nasal congestion. It is triggered by some noxious stimuli like tight clothes, full bladder; severe pain etc. It is managed by removal of noxious stimuli, e.g. loosen tight clothing, empty bladder, bowel disimpaction etc. If needed give antihypertensive. Realizing the need of awareness of Spinal 
Cord injury The International Spinal Cord Society has decided to observe 5th September every year as SCI day [1]. Hence, the spine patients need more precise care and should have some knowledge regarding the same.

This work is licensed under Creative Commons Attribution 4.0 License

DOI: $10.19080 / O R O A J .2017 .08 .555726$

\section{References}

1. Chhabra HS, Batra S (2016) Spinal Cord Injury and its Impact on the patient, Family and the society. Int J Recent Surg Med Sci 2(1): 1-4.

\section{Your next submission with Juniper Publishers will reach you the below assets}

- Quality Editorial service

- Swift Peer Review

- Reprints availability

- E-prints Service

- Manuscript Podcast for convenient understanding

- Global attainment for your research

- Manuscript accessibility in different formats

( Pdf, E-pub, Full Text, Audio)

- Unceasing customer service

Track the below URL for one-step submission https://juniperpublishers.com/online-submission.php 